\title{
Impact of mass media on Knowledge attitude and practices (KAP) amongst the ANC mothers attending the ICTC at DrRPG Medical College, Tanda
}

\author{
Anamika Chanchal ${ }^{1}$, Sanjay Bhonge ${ }^{2}$, Rajaram Gavade ${ }^{3}$, Deepak Raut ${ }^{4}$, Dinesh Kansal ${ }^{5, *}$ \\ ${ }^{1}$ Health Educator, ${ }^{2}$ Social Worker, ${ }^{3}$ Statistical Asisstant, ${ }^{4}$ Director, ${ }^{5}$ Professor \& HOD, Dept. of Pharmacology, ${ }^{1,5}$ Dr. Rajendra \\ Prasad Government Medical College Kangra, Himachal Pradesh, ${ }^{2,3,4}$ Family Welfare Training \& Research Centre, Mumbai, \\ Maharashtra, India
}

*Corresponding Author:

Email: dinesh.kansal56@gmail.com

\begin{abstract}
Objectives: To know the Impact of Mass Media on Knowledge attitude and practices (KAP) amongst the ANC mothers attending the ICTC at DrRPG Medical College, Tanda.

Materials and Methods: This was a Hospital based, cross sectional study. The data was collected from pregnant women attending outpatient antenatal care (ANC) with prior written informed consent, from August 2017 to September 2017. A semi structured survey questionnaire was prepared for the study containing 54 questions regarding demographic information, HIV/STD information sources, HIV transmission knowledge, Misconceptions and attitude towards PLHIV. The questionnaire was administered as a face-to-face personal interview, and participant answers were filled in by interviewers.

Results: Mass media sources, such as TV programs, newspapers and magazines, were more frequently identified as the channels for HIV information than interpersonal sources, such as friends and service providers. Exposure to multiple sources of HIV information (where at least one source is mass media) was significantly related to HIV knowledge. Yet it is observed that the knowledge of transmission of HIV from mother to child is seen less than other mode of transmission amongst the ANC mothers. It is also seen that though the mothers know that the HIV testing is required but are not aware about the ICTC and its role. Even after so much of communication regarding the misconceptions, some misconceptions still exist among the ANC mothers.

Conclusion: Even though mass media have played important role to increase knowledge about HIV, there is need to create a supportive health promotion education mechanism in the form of Health educators at grass root level, who can do intensified social behavioural communication campaigning to bring about the expected behaviour changes by providing correct knowledge about the mother to child transmission of HIV/AIDS, Use of Condom, and to remove the misconception regarding the mode of transmission of the HIV/AIDS.
\end{abstract}

Keywords: HIV, Mass media, Knowledge.

\section{Introduction}

Acquired Immune Deficiency Syndrome (AIDS) is a fatal illness caused by retrovirus known as Human Immunodeficiency Virus (HIV). It is a pandemic disease without borders and is currently in its fourth decade. Globally, more than 35.3 million people are currently living with HIV infection. According to WHO, there are an estimated four million people living with HIV(PLHIV) in the South-East Asia Region, constituting nearly $11.8 \%$ of PLHIV globally. In India, there are nearly 2.12 million PLHIV and 0.9 million are on treatment. As per NACO annual report 2012-13, HIV prevalence in India is $0.3 \%{ }^{1}$

HIV was first detected in India in 1986 when pilot surveillance activities were carried out among selected population and in various locations to ascertain if the virus was present in the country. Within six or seven years, it became evident that HIV infection was present in almost all parts of country, but was worst in states of Maharashtra, Tamil Nadu, and northern states of Manipur, Mizoram and Nagaland .In the latter three states, which border Myanmar, the main mode of HIV transmission is through needle sharing by injecting drug users, whereas in the rest of the country, most infections are transmitted through heterosexuals. The number of AIDS cases reported from all part of the country is increasing. ${ }^{2}$

In statistics of the world epidemic of HIV/AIDS as published by UNAIDS/WHO in Nov 2010, states that 33.2 million people were living with HIV, 2.7 million became newly infected with the virus, and 2 million people died of HIV related causes in a year. There is an increase in the number of children infected with HIV in recent years as the number of HIV positive women has increased. More than $90 \%$ of HIV infections in children aged less than 15 years are due to mother-to-child transmission (MTCT) of HIV. ${ }^{3}$

India accounts for about $7 \%$ of all HIV/AIDS cases in the world. ${ }^{4}$ Globally, women constitute $48 \%$ of adults infected with HIV; in India, they constitute 39\%.The prevalence is highest among productive young people between the ages of 20 and 29 years, with $60 \%$ of new infections occurring in the 15-25 years age group., Women are now considered the face of HIV infection accounting for half of all infections worldwide and 57\% of infections in sub-Saharan Africa. Heterosexual transmission accounts for $84 \%$ of cases in India and HIV is spreading rapidly in married women, who were previously considered to be at low risk. It causes 
morbidity and mortality of infants and children, pertaining to its MTCT risk. MTCT which occur during pregnancy, labour and breastfeeding, is responsible for $90 \%$ childhood HIV infection. The main objective of the prevention is to reduce the transmission of HIV infection from HIV infected mothers to their off springs. However, it is to be noted that the most important public health measures are prevention of infections in women of childbearing age and the prevention of unwanted pregnancies through adequate family planning. ${ }^{7}$

The prevention of HIV transmission from mothers to their infants is built around the routine counselling and testing of all pregnant women along with other interventions. These programs are potentially the most effective interventions in reducing maternal, neonatal and child morbidity and mortality. These will be implemented with the routine ANC services. ${ }^{8}$

As per NFHS-IV data $20.9 \%$ of women and $32.3 \%$ of men have comprehensive knowledge of HIV/AIDS and $30.9 \%$ of women and $44.5 \%$ of men in Himachal Pradesh have comprehensive knowledge of HIV/AIDS. ${ }^{9}$

Mass media have the ability to reach remote areas as they are easily accessible to the audience. Hence Mass media sources, such as TV programs, newspapers and magazines, were more frequently identified as the channels for HIV information than interpersonal sources, such as friends and service providers. Exposure to multiple sources of HIV information (where at least one source is mass media) was significantly related to HIV knowledge. The agencies like NACO, Ministry of Health \& Family Welfare, encourage use of the mass media for showing advertisements and programs to create awareness about the mode of transmission of HIV infection, Prevention, Testing of HIV, and creating positive attitude amongst the community. Communication campaign through various mass media has played an important role for HIV/AIDS awareness and its prevention.

\section{Aims and Objectives}

1. To understand the source of information on HIV/AIDS and the KAP amongst the ANC mothers attending the ICTC centre at DrRPG Medical College, Tanda for the HIV testing.

2. Determine the association between source of HIV information and HIV knowledge, misconception about the mode of transmission, attitude towards PLHIV and practices about the condom use.

\section{Materials and Methods}

This was a hospital based, cross sectional study. The data was collected from pregnant women attending outpatient antenatal care (ANC) with prior written informed consent, from August 2017 to September 2017. A semi structured survey questionnaire was prepared for the study containing 54 questions regarding demographic information, HIV/STD information sources, HIV transmission knowledge, misconceptions and attitude towards PLHIV. The questionnaire was administered as a face-to-face personal interview, and participant answers were filled in by interviewers.

The Ethical approval and clearance was taken from Ethical committee of DrRPG Medical College Tanda vide letter no. HFW-H-DRPGMC/Ethics/2017-5352 dated 06/11/2017.

\section{Sample size calculation}

Based on assumption that about 38.0 percent pregnant women have knowledge about HIV/AIDS (According to NFHS-4) a sample size of about 181 women was calculated with 80.0 percent study power, 10 percent precision and at 5 percent level of significance. Purposive sampling method was utilized for sample collection.

Exclusion Criteria: Women with emergency / recommended for admission for immediate management.

\section{Ethical issues}

This study did not cost additional expenses on the study subjects. There were no potential risks that might cause any harm to the study subjects. Information which was communicated by the subjects was kept private and confidentiality was maintained. Coding was used to eliminate names and other personal identification of respondents throughout the study process to ensure anonymity.

\section{Data analysis}

All analyses were performed using Excel and SPSS software. Descriptive statistics were used to describe demographics and sources of HIV/STD information.

Table 1. Socio Demographic distribution of respondents

\begin{tabular}{|l|l|c|c|}
\hline \multicolumn{2}{|c|}{ Variable } & Frequency & Percentage \\
\hline \multirow{3}{*}{ Age (Years) } & $21-30$ & 1 & 0.6 \\
\cline { 2 - 4 } & $31-40$ & 146 & 80.7 \\
\cline { 2 - 4 } & $41-50$ & 34 & 18.8 \\
\hline \multirow{3}{*}{ Education } & Illiterate & 4 & 2.2 \\
\cline { 2 - 4 } & Below SSC & 11 & 6.1 \\
\cline { 2 - 4 } & SSC & 33 & 18.2 \\
\hline
\end{tabular}




\begin{tabular}{|l|l|c|c|}
\hline \multirow{4}{*}{ Occupation } & HSC & 82 & 45.3 \\
\cline { 2 - 4 } & Graduate \& above & 51 & 28.2 \\
\cline { 2 - 4 } & Home maker & 166 & 91.7 \\
\cline { 2 - 4 } & Labour & 3 & 1.7 \\
\cline { 2 - 4 } & Govt. Service & 4 & 2.2 \\
\cline { 2 - 4 } & Farming & 1 & 0.6 \\
\cline { 2 - 4 } & Semi skilled worker & 1 & 0.6 \\
\cline { 2 - 4 } & Private Job & 6 & 3.3 \\
\hline \multirow{4}{*}{ Income } & $0-5000$ & 41 & 22.7 \\
\cline { 2 - 4 } & $5001-10000$ & 71 & 39.2 \\
\cline { 2 - 4 } & $10001-20000$ & 35 & 19.3 \\
\cline { 2 - 4 } & $>20000$ & 34 & 18.8 \\
\hline Caste & SC & 28 & 15.5 \\
\cline { 2 - 4 } & OBC & 80 & 44.2 \\
\cline { 2 - 4 } & General & 63 & 34.8 \\
\cline { 2 - 4 } & ST & 10 & 5.5 \\
\hline
\end{tabular}

The demographic distribution of the study participants showed that $146(80.7 \%)$ participants were from the age group of 31-40. Out of 181 participants only $4(2.2 \%)$ were illiterate, while $82(45.3 \%)$ participants were educated up to intermediate level and $51(28.2 \%)$ were graduation \& above. The women who participated in the study were mostly house wives
$166(91.7 \%)$, only $4(2.2 \%)$ were Government employees. Family income was in range of $0-5000$ per month in $41(22.7 \%)$ women and $34(18.8 \%)$ were having family income more than 20,000. The cast distribution shows that $80(44.2 \%)$ women belonged to other backward class and 63(34.8\%) were from general category.

Table 2: Distribution of respondents according to their knowledge regarding prevention measures about HIV

\begin{tabular}{|l|c|c|c|c|c|c|}
\hline Knowledge About HIV & \multicolumn{2}{|c|}{ Yes } & \multicolumn{2}{c|}{ No } & \multicolumn{2}{c|}{ Don't know } \\
\cline { 2 - 7 } & $\mathbf{N}$ & $\mathbf{\%}$ & $\mathbf{N}$ & $\mathbf{\%}$ & $\mathbf{N}$ & $\mathbf{\%}$ \\
\hline Heard about HIV/AIDS & 171 & 94.5 & 1 & 0.6 & 9 & 5.0 \\
\hline $\begin{array}{l}\text { Can be prevented by properly using } \\
\text { condom during sexual intercourse }\end{array}$ & 132 & 72.9 & 11 & 6.1 & 38 & 21.0 \\
\hline $\begin{array}{l}\text { Transmission can be avoided by } \\
\text { remaining faithful to a single partner }\end{array}$ & 153 & 84.5 & 2 & 1.1 & 26 & 14.4 \\
\hline Information about HIV test & 133 & 73.5 & 32 & 17.7 & 16 & 8.8 \\
\hline Knowledge of ICTC & 17 & 9.4 & 152 & 84.0 & 12 & 6.6 \\
\hline HIV testing is free of cost in ICTC & 137 & 75.7 & 8 & 4.4 & 36 & 19.9 \\
\hline $\begin{array}{l}\text { HIV testing is mandatory during } \\
\text { pregnancy }\end{array}$ & 144 & 79.6 & 7 & 3.9 & 30 & 16.6 \\
\hline
\end{tabular}

171(94.5\%) pregnant women had heard about the HIV/AIDS before visiting the ICTC. 132(72.9\%) women were aware that the use of condom can prevent transmission of HIV/AIDS and $153(84.5 \%)$ said that it can be prevented by remaining faithful with single partner. It was found that $133(73.5 \%)$ women knew about the HIV test, 144(79.6\%) were aware that it is mandatory during pregnancy. 137(75.7\%) women knew that the test at the ICTC was free of cost. But 152(84\%) women said that they didn't know what ICTC is.

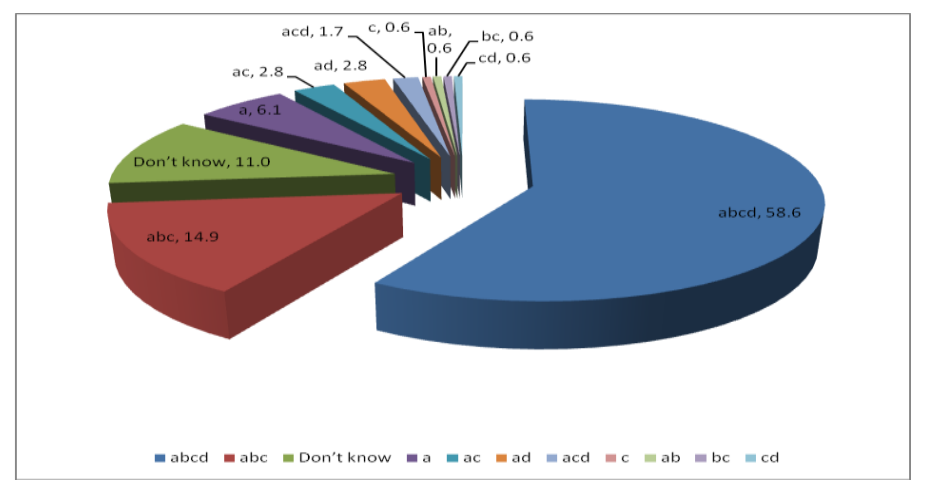

Fig. 1: Distribution of respondents Knowledge about mode of transmission of HIV 
Unprotected sex, b- Unsafe / infected blood \& products, c-Infected needles, d- Infected mother to child.

According to the study data $106(58.6 \%)$ mothers knew all the modes of HIV transmission correctly, $27(14.9 \%)$ mothers knew three modes of transmission i.e. unprotected sex, unsafe/infected blood products and infected needles. 20(11.1\%) didn't know any mode of transmission, where as $5(2.8 \%)$ mothers knew about unprotected sex and infected mother to child transmission.

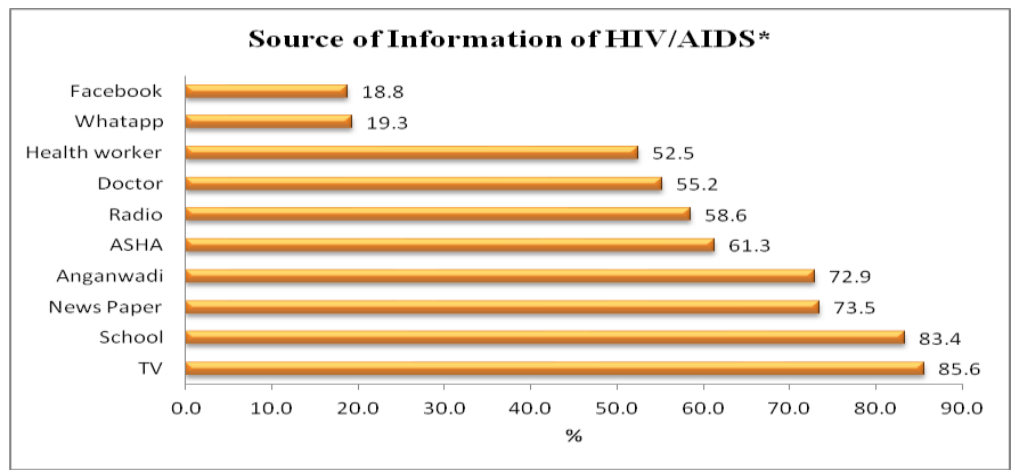

Fig. 2: Distribution of the respondents according to the Source of Information about HIV

Percentage score is higher than $100 \%$ because multiple answers were allowed and some respondents listed more than one recent source of information about HIV/AIDS.

The majority of pregnant women stated that they obtained information from Television 155(85.6\%) and
School 151(83.4\%), which includes advertisement by Government or informative program on T.V. Newspapers and persons related to health also play significant role in giving information about HIV/AIDS. The percentage distribution of Interpersonal communication from Health Worker, Doctor, Asha and Anganwadi worker was between $52.5 \%$ to $72.9 \%$.

Table 3: Association of Source of information and correct knowledge about prevention about HIV amongst the pregnant women

\begin{tabular}{|c|c|c|c|c|c|}
\hline \multicolumn{6}{|c|}{ Knowledge about HIV } \\
\hline \multicolumn{2}{|r|}{ Variable } & $\begin{array}{l}\text { Can be prevented } \\
\text { by properly using }\end{array}$ & $\begin{array}{c}\text { Transmission can } \\
\text { be avoided by }\end{array}$ & Information & Knowledge \\
\hline \multirow{10}{*}{ 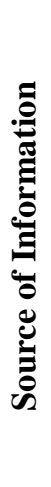 } & Anganwadi & 77.3 & 90.2 & 76.5 & 9.8 \\
\hline & Doctor & 81.0 & 94.0 & 87.0 & 12.0 \\
\hline & $\mathrm{TV}$ & 79.4 & 91.6 & 77.4 & 8.4 \\
\hline & Face book & 85.3 & 100.0 & 85.3 & 23.5 \\
\hline & $\begin{array}{l}\text { Health } \\
\text { worker }\end{array}$ & 80.0 & 92.6 & 81.1 & 11.6 \\
\hline & ASHA & 79.3 & 93.7 & 82.0 & 10.8 \\
\hline & Radio & 81.1 & 93.4 & 77.4 & 9.4 \\
\hline & WhatsApp & 85.7 & 94.3 & 91.4 & 22.9 \\
\hline & $\begin{array}{l}\text { News } \\
\text { Paper }\end{array}$ & 80.5 & 94.7 & 82.0 & 11.3 \\
\hline & School & 80.1 & 92.1 & 79.5 & 9.9 \\
\hline
\end{tabular}

*all numbers are in \%

The comparative table of source of information and correct knowledge about the prevention of HIV infection shows that near about $80 \%$ of the ANC mother had the correct knowledge regarding the proper use of condom can prevent HIV infection and more than $90 \%$ had the knowledge about remaining faithful to single partner can prevent HIV infection. More than $75 \%$ had information about the HIV test from the different media. Though they knew about the HIV test, it was observed that the knowledge about ICTC was very poor in ANC mothers exposed to all media. 
Table 4: Distribution of the respondents according to misconceptions about HIV AIDS

\begin{tabular}{|l|l|c|c|}
\hline Misconceptions about HIV AIDS & N & \% \\
\hline HIV Transmission & By Shaking Hand & 27 & 14.9 \\
\cline { 2 - 4 } & $\begin{array}{l}\text { By eating \& drinking from } \\
\text { same plate }\end{array}$ & 34 & 18.8 \\
\cline { 2 - 4 } & $\begin{array}{l}\text { Wearing Same clothes of } \\
\text { HIV person }\end{array}$ & 30 & 16.6 \\
\cline { 2 - 4 } & $\begin{array}{l}\text { Sharing a Toilet with HIV } \\
\text { person }\end{array}$ & 36 & 19.9 \\
\cline { 2 - 4 } & Through mosquito bite & 70 & 38.7 \\
\hline
\end{tabular}

The table about the misconception revealed that $38.7 \%$ participants believe that through mosquito bite they can be affected. While 19.9 still believe that sharing a toilet can infect them. Wearing cloths of infected person, eating and drinking in same plate or shaking hands can transmit infection are some other misconception still prevailing in amongst women.

Table 5: Association between Source of Information and misconception about HIV amongst the respondents

\begin{tabular}{|c|c|c|c|c|c|c|}
\hline \multicolumn{2}{|c|}{ 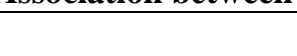 } & \multicolumn{5}{|c|}{ Misconceptions } \\
\hline & Variable & $\begin{array}{c}\text { By } \\
\text { Shaking } \\
\text { Hand }\end{array}$ & $\begin{array}{l}\text { By eating \& } \\
\text { drinking from } \\
\text { same plate }\end{array}$ & $\begin{array}{c}\text { Wearing } \\
\text { Same clothes } \\
\text { of HIV person }\end{array}$ & $\begin{array}{l}\text { Sharing a } \\
\text { Toilet with } \\
\text { HIV person }\end{array}$ & $\begin{array}{c}\text { Through } \\
\text { mosquito } \\
\text { bite }\end{array}$ \\
\hline \multirow{10}{*}{ 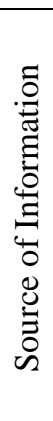 } & Anganwadi & 15.9 & 19.7 & 16.7 & 23.5 & 36.4 \\
\hline & Doctor & 17.0 & 19.0 & 15.0 & 17.0 & 36.0 \\
\hline & TV & 16.8 & 20.0 & 18.7 & 21.9 & 41.9 \\
\hline & Face book & 14.7 & 14.7 & 11.8 & 38.2 & 41.2 \\
\hline & Health worker & 16.8 & 16.8 & 15.8 & 23.2 & 35.8 \\
\hline & ASHA & 17.1 & 21.6 & 18.0 & 24.3 & 39.6 \\
\hline & Radio & 15.1 & 20.8 & 16.0 & 23.6 & 39.6 \\
\hline & WhatsApp & 11.4 & 17.1 & 8.6 & 28.6 & 42.9 \\
\hline & News Paper & 14.3 & 18.8 & 15.8 & 23.3 & 38.3 \\
\hline & School & 15.9 & 19.2 & 17.2 & 21.2 & 39.1 \\
\hline
\end{tabular}

Table 6: Distribution of respondents Attitude towards HIV positive person

\begin{tabular}{|l|c|c|c|c|c|c|}
\hline \multirow{2}{*}{ Attitude towards HIV positive person } & \multicolumn{2}{|c|}{ Yes } & \multicolumn{2}{c|}{ No } & \multicolumn{2}{c|}{ Don't know } \\
\cline { 2 - 7 } & $\mathbf{N}$ & $\mathbf{\%}$ & $\mathbf{N}$ & $\mathbf{\%}$ & $\mathbf{N}$ & $\mathbf{\%}$ \\
\hline Necessary to know about HIV status & 171 & 94.5 & 0 & 0 & 10 & 5.5 \\
\hline $\begin{array}{l}\text { Would you willing to care for relative HIV } \\
\text { person in your home/community }\end{array}$ & 174 & 96.1 & 6 & 3.3 & 1 & 0.6 \\
\hline Would you continue your friendship & 163 & 90.1 & 17 & 9.4 & 1 & 0.6 \\
\hline Would you buy items from him/her & 128 & 70.7 & 50 & 27.6 & 3 & 1.7 \\
\hline $\begin{array}{l}\text { Would you allow to continue studies in } \\
\text { school/college }\end{array}$ & 150 & 82.9 & 24 & 13.3 & 7 & 3.9 \\
\hline
\end{tabular}

According to the study data the respondent regarding attitude it is found that 171(94.5\%) ANC mothers said that it is necessary to know about HIV status. Out of 181 respondents 174(96.1\%) expressed their willingness to care for the HIV positive person if found in the home/community and 163(90.1\%) said they would continue friendship with the HIV positive person. When asked about that whether HIV positive person should be allowed to continue education with others in School/ College 150(82.9\%) said yes.

Table 7: Distribution of the respondents according to their practices pertaining to voluntary testing and prevention of HIV Practice ( $n=181)$

\begin{tabular}{|l|c|c|}
\hline \multicolumn{1}{|c|}{ Practice } & Frequency & Percentage \\
\hline If doctor couldn't send u for HIV test would u go for it by yourself \\
\hline Yes & 112 & 61.9 \\
\hline No & 69 & 38.1 \\
\hline Do you think your partner should be informed about the result of the test \\
\hline
\end{tabular}




\begin{tabular}{|c|c|c|c|}
\hline \multicolumn{2}{|l|}{ Yes } & 181 & 100.0 \\
\hline \multicolumn{4}{|c|}{ Do you agree with volunteer HIV testing } \\
\hline \multicolumn{2}{|c|}{ Yes } & 164 & 90.6 \\
\hline \multicolumn{2}{|l|}{ No } & 6 & 3.3 \\
\hline \multicolumn{2}{|l|}{ Don't know } & 11 & 6.1 \\
\hline \multicolumn{4}{|c|}{ Use of Condom regularly during sexual intercourse } \\
\hline & Yes & 74 & 40.9 \\
\hline & No & 107 & 59.1 \\
\hline
\end{tabular}

In this study, out of 181 participants $112(69.9 \%)$ said that if doctor couldn't send them for HIV testing they will go voluntarily. When they were asked about informing their partner about the result of HIV test, all $181(100 \%)$ said that yes partner should be informed. Out of 181 respondents only, 74(40.9\%) said that their partners are regularly using condom during sexual intercourse.

\section{Discussion}

The study assessed the Knowledge, attitude and practices amongst the ANC mothers attending the obstetrics and gynaecology, outpatient department at Tanda Medical College. The study tried to explore the correlation between the knowledge amongst the ANC mothers and source of information of HIV. In this study most of the mothers were exposed to the multiple channel of mass communication compared to the interpersonal channel and they got the information regarding the main mode of transmission of HIV infection i.e. unprotected sex, from these mass media. Yet it is also seen that compared to the sexual mode of transmission the knowledge regarding the mother to child transmission was less. Though results are similar to the other studies conducted in India and abroad it can be said that the information regarding the transmission of mother to child couldn't reach up to the target audience.

During the study the majority of mothers responded that TV as major source of information. The demographic data revealed that the mothers participated in the study were housewives and have ample time and access to the television media in their leisure time after their household work. Hence it can be said that the campaigning through television media in the form of advertisement resulted in the increase of knowledge about the HIV.

According to the analysis of the results of the data regarding the misconceptions about the transmission of the HIV infection it has been observed that 38\% (70) ANC mothers still believed that mosquito bite can transmit, whereas other misconception still exist in the range of $14.9 \%$ to $19.9 \%$ such as by shaking hand and sharing toilet. Correlation in between source of information and misconception, irrespective of source of the information the percentage distribution of the respondents who were having misconceptions remained in the range of $36 \%$ to $41.9 \%$ which implies though the communication sources has influenced the knowledge regarding the mode of transmission, based on our analyses, it couldn't remove the misconception.

The assessment of data about the attitude toward the HIV infected person shows positive attitude. This shows that the communication campaigns have produced good results in term of bringing about positive changes amongst the ANC mothers. In this study it is found that though the knowledge regarding the regular use of condom for the prevention of the HIV is increased, the use of condom is less. This may be because it also depends on the attitude and knowledge of the partner.

Hence it can be concluded that even though the mass media have played important role to knowledge increase about HIV, there is need to create a supportive health promotion education mechanism in the form of Health educators at grass root level, who can do intensified social behavioural communication campaigning to bring about the expected behaviour changes by providing correct knowledge about the mother to child transmission of HIV/AIDS, use of condom, and to remove the misconceptions regarding the mode of transmission of the HIV/AIDS.

\section{References}

1. Bansal K, Aggarwal R, Chaudhary U, Kumar V. Knowledge, Attitude and Practices (KAP) among the voluntary attendees of Integrated Counseling and Testing Centre (ICTC) of a Teaching Tertiary Care Hospital of North India. PGIMS, Rohtak, Haryana. IOSR Journal of Dental and Medical Sciences. Volume 15, Issue 11 Ver. VI (November. 2016), PP 20-25.

2. Lal S and Thakur BB The Problem of HIV and AIDS in India, National AIDS Control Organization, Ministry of Health \&Family Welfare, IRCS Building, 1 Red Cross Road, New Delhi-1100001 India (special section : AIDS in ASIA)

3. Shree V, Prasad RR, Awareness of HIV/AIDS amongst Pregnant Women of Rural Areas Patna: A CommunityBased Study, International Journal of Science and Research(IJSR)ISSN (online):2319-7064

4. Joint United Nations Programe on HIV/AIDS (UNAIDS) Report on the global AIDS epidemic 2008. Available from: http://www.unaids.org/en/ KnowledgeCentre/HIVData/GlobalReport/2008/2008_ Global_report.asp [accessed on 2017 July 16].

5. National AIDS Control Organization(NACO).Annual HIV Sentinel Surveillance country Report 2006,Available from:http://www.nacoonline.org/upload/ [accessed on 2017 july 17]

6. US aids International development (USAIDS). India country profile (HIV/AIDS),2008.Available from 
:http://www.usaid.gov/location/asia/countries/india [accessed on 2017 july 19]

7. Udaykiran U, Bhagle, Gautam M, Khaske, Kishor P, Brahmapurkar, Ravinder Thorat, Vaishali K. Short Awareness Regarding HIV / AIDS in ANC Client in Tribal District Of Central India. IOSR Journal of Dental and Medical Sciences (JDMS) ISSN: 2279-0853, ISBN: 2279-0861. Volume 2, Issue 4 (Nov.- Dec. 2012), PP 44 49.

8. GebreY, Itayih and Astede Fantahun, Assesment of knowledge, Attitude and Practice of HIV prevention of mother to child among pregnant women attending Ayder referral hospital, Mekelle, Ethiopia. International journal of Medical and Biomedical Sciences.

9. NFHS -IV Analysis, State fact sheet Himachal Pradesh, 2015-16, Ministry of health and family welfare, Government of India. 